\title{
Air pollutant deposition effect and morphological change of Cryptomeria japonica pollen during its transport in urban and mountainous areas of Japan
}

\author{
Q. Wang ${ }^{1}$, X. Gong ${ }^{1}$, S. Nakamura ${ }^{1}$, K. Kurihara ${ }^{1}$, M. Suzuki ${ }^{1}$, \\ K. Sakamoto ${ }^{1}$, M. Miwa ${ }^{2} \&$ S. Lu ${ }^{3}$ \\ ${ }^{1}$ Graduate School of Science \& Engineering, Saitama University, Japan \\ ${ }^{2}$ Center for Environmental Science in Saitama, Japan \\ ${ }^{3}$ School of Environmental \& Chemical Engineering, \\ Shanghai University, China
}

\begin{abstract}
Morbidity due to Cryptomeria japonica pollinosis is increasing, especially in the urban areas of Japan. It represents a major health problem for most modern societies. The reasons for this increase might be the association of pollen with air pollutants. Hyper-reactivity tests are being conducted on mice and rats for allergic immune response. However, such tests cannot evaluate the deposition of pollen to the respiratory tract, because they force the animals to be immunized to pollen allergen mixed with air pollutants separately. The purpose of this study is to investigate how air pollutants deposit onto airborne Cryptomeria japonica pollen grains during the pollen-flying season between urban and mountainous areas, and to aid further bioreactivity and hypersensitive research. Suspended particulate matter (SPM), Cryptomeria japonica perigonium and pollen grains were collected to identify the deposition of air pollutants in an urban area, Saitama City, and in a mountainous area, Okuchichibu, during the pollen flying seasons. Ionic and metallic components of SPM and perigonium and pollen grains were analyzed. We found that crustal components ( $\mathrm{Al}, \mathrm{Fe}$ and $\mathrm{Ti}$ ) tended to deposit on pollen perigonium. The amount of ionic components of particles $\left(\mathrm{NO}_{3}{ }^{-}, \mathrm{SO}_{4}{ }^{2-}\right.$ and $\left.\mathrm{NH}_{4}{ }^{+}\right)$and gaseous pollutants $\left(\mathrm{NO}_{2}, \mathrm{SO}_{2}\right.$ and $\left.\mathrm{NH}_{3}\right)$ deposited on the perigonium and pollen grains were higher in the urban than in the mountainous areas, the results of which was proven by determination of gaseous
\end{abstract}


pollutants exposed to Cryptomeria japonica pollen. It is suggested that these phenomena may affect the pollinosis and therefore it is necessary to investigate implications on further bioreactivity and hypersensitive research.

Keywords: Cryptomeria japonica pollen, perigonium, allergen, suspended particulate matter, ionic and crustal components, gaseous pollutants.

\section{Introduction}

The prevalence of allergic diseases has increased worldwide during the last decades. In Japan, more than 10-20\% adults and 5-10\% or more in children are said to be afflicted with the disease referred to as 'Japanese Cedar Pollinosis' which is the allergic disease suffered from Cryptomeria japonica pollen. There is evidence that air pollution enhances not only the risk of allergy but may also be responsible for increasing prevalence rates of pollen allergies in highly polluted regions (Maejima et al., Japan Automobile Research Institute [1]). Moreover, the increasing tendency of the number of hay fever patients is notably seen especially in urban areas and the prevalence of Tokyo reaches about $28 \%$ (Bureau of social welfare and public health, 2007 [2]). Therefore, it is thought that air pollution is one of the causes. Studies on the relativity of the pollinosis with air pollution have been carried out by animal tests. When the Japanese cedar pollen and air pollutants are prescribed to animals simultaneously, it was reported that the $\mathrm{NO}_{2}$ adjuvant effect which deteriorates symptom synergistically happens (Uchiyama et al. [3]).

It has been shown that pollutant gases (i.e. $\mathrm{SO}_{2}, \mathrm{NOx}$ and $\mathrm{O}_{3}$ ) and suspended particulate matter (SPM) (e.g. organic compounds, diesel exhaust particulates (DEPs)) (Sakamoto et al. [4]) and crustal dust (Wang and Sakamoto [5], Wang et al. [6], Sakamoto and Wang [7]) have both adjuvant activity for specific IgE production against common bioaerosols in experimental animals and enhancing effects on allergic symptoms within sensitized individuals (Conner and Norris [8]). Furthermore, pollen grains do not only carry bioaerosols, but also incorporate pollutants when released into a polluted atmosphere (Behrendt and Becker [9]). Pollen grains (particles) can accumulate heavy metals, i.e., lead, cadmium, and mercury, as well as sulfur compounds. However, there was only one report of metallic elements on the surface of Japanese Cedar pollen (Okuyama et al. [10]). The question to be answered is whether air pollutants are able to alter/impair structure and function of the pollen itself. To answer this we should know allergen formation, and release, related to air pollution.

In this research, we try to find the deposition of various air pollutants on Cryptomeria japonica perigonium and pollen grains, and discuss several concepts of an interaction between the pollen and pollutants. Some exposure experiments of pollens to air pollutants in the roadside (Jiang et al. [11]) and laboratory and morphological analysis by an electron microscope are carried out, and ionic and elemental analyses of the pollen grains collected in urban and mountainous areas of Saitama, Japan are performed. 


\section{Experiment methods}

\subsection{Collection of pollen perigonium, pollen grains and SPM samples}

For in-situ detection of pollen-SPM interaction, some Crptomeria japonica pollen perigonium (Japanese cedar pollen) were collected at trees growing in Akigase Park, an urban area, near Rokken Road (route 57) of Saitama City with heavy traffic, as well as at Okuchichibu, a mountainous area, during spring 2003-2005. The pollen samplers (Nishiseiki Co. Ltd., Durham model DK-1SA) were set beside the roadside of route 57 to collect cedar pollen grain samples. In addition, some cedar pollen grain samples for exposure experiment were obtained from Japan Automobile Research Institute collected in a rural site of Yamagata, Japan. Five size-segregated SPM samples were collected on tissuequartz filters according to their diameters into five size fractions from coarse to fine (equivalent aerodynamic diameters $(D p)<1.1,1.1-2.0,2.0-3.3,3.3-7.0$ and $>7.0 \mu \mathrm{m}$ ) using the high volume air samplers (SHIBATA Co. Ltd., AH-600) with a flow rate of $566 \mathrm{~L} \mathrm{~min}^{-1}$ for several 23 hour or 47 hour durations during the pollen flying seasons of March, 2004-2006 in urban and mountainous areas.

\subsection{Exposure experimental design and chemical analyses of pollen and SPM}

The pollen grain samples were exposed up to 9 hours on the roadside to heavy traffic and polluted urban atmosphere to find any morphological changes in pollen surface or vitality. Before and after the exposure of pollen grains near the roadside, they were collected and preserved for the pollen surface observation. At same time, exposure equipment was prepared in the laboratory for analyzing adsorption of gaseous pollutants (Gas monitors for $\mathrm{NO}_{2}$ (Model-265p), $\mathrm{SO}_{2}$ (FLAT1000) and $\mathrm{NH}_{3}$ (Model 17)) on the pollen grains by the exposure experimental chamber. The tissue-quartz filters of five size-segregated SPM samples obtained by the AH-600 air samplers have been punched in four portions for separate chemical determinations of the ionic and metallic components, morphological observation by a scanning electron microscopy and reserve. Concentrations of carbon $(\mathrm{C})$, hydrogen $(\mathrm{H})$ and nitrogen $(\mathrm{N})$ of the pollen samples were analyzed by a CHN corder (Yanaco Co. Ltd., Model MT-3). We also analyzed all loaded filters for total organic carbon (TOC) and total elemental carbon (TEC) using a thermal optical carbon analyzer (DRI model 2001, Shibata Scientific Technology Ltd.). The IMPROVE thermal/optical reflectance protocol was used for the carbon analysis. The repeatability, determined from replicate analyses, was better than 5\% for total carbon (TC) and $10 \%$ for OC and EC. An ion chromatograph (Dionex Co., DX-100) was used for analysis of ionic components $\left(\mathrm{NO}_{3}{ }^{-}, \mathrm{SO}_{4}{ }^{2-}\right.$, and $\mathrm{Cl}^{-}$and $\left.\mathrm{NH}_{4}{ }^{+}\right)$. The elements extracted by a strong acid digestion procedure were determined with an inductively coupled argon plasma atomic emission spectrometer (ICP-AES, JICP-PS1000UV). Field blanks were also analyzed, and the resulting values were subtracted from the analytical results for the respective samples. 


\subsection{Morphological observation on the surface of collected pollen particles}

After or before the exposure experiments, the pollen grains were analyzed morphologically by a light microscopy and a scanning electron microscope (SEM, Hitachi Co. Ltd., Model S-2400), with imaging to study the morphology of the gold labelled SPM particles. Prepared pollen grain samples were fixed with glutaraldehyde, post fixed with osmium, dehydrated, and dried prior to gold coating. After the gold coating procedure, samples were directly observed morphologically $(\times 300-\times 30,000)$ using the SEM.

\section{Results and discussion}

\subsection{Air pollutants between urban and mountainous areas of Japan}

In order to evaluate the influence of allergen particles for a development of pollinosis, pollen asthma and the modification of allergen particles with air pollutants, in this study, we firstly carried out about the air pollutant concentrations for comparison examination between urban and mountainous areas of Japan.

As shown in figures 1 and 2, size-distributions of ionic air pollutants $\left(\mathrm{NH}_{4}{ }^{+}\right.$, $\mathrm{SO}_{4}{ }^{2-}, \mathrm{NO}_{3}{ }^{-}$and $\mathrm{Cl}$ ), the average high levels of $\mathrm{Al}, \mathrm{Fe}, \mathrm{Ti}$, and $\mathrm{SO}_{4}{ }^{2-}, \mathrm{NO}_{3}{ }^{-}$ and $\mathrm{NH}_{4}^{+}$) were determined. Consequently, it was observed that SPM concentrations are higher in urban area than those in mountainous area.

For investigation of the secondary formed fine particles, the concentrations of $\mathrm{SO}_{4}{ }^{2-}, \mathrm{NO}_{3}{ }^{-}$and $\mathrm{NH}_{4}{ }^{+}$in fine particles below $2.0 \mu \mathrm{m}$ in air polluted urban area were higher about 2-4 times compared with those in mountainous area. It is also thought that high crustal particles and road dust are able to be winded up caused from the heavy traffic and strong wind speed beyond $6 \mathrm{~m} \mathrm{~s}^{-1}$ in urban area.

In Japan, although clean air policies have been very successful and the emission of traffic and $\mathrm{SO}_{2}$ has diminished progressively, however, emissions from heavy duty vehicles, especially total elemental carbon (TEC) as a tracer of diesel exhaust particulates (DEPs) are 2-3 times higher in urban area given in figure 3 estimated ca. 20-30\% of SPM in the ambient air over Japan (Wang and Sakamoto [12]). Human exposure to air pollutants is determined by concentrations both outdoors and indoors. Moreover, outdoor air pollution including bioaerosols (i.e., aeroallergens) is brought into the indoor environment by natural and mechanical ventilation.

\subsection{Morphological observation for pollen grain, perigonium and its surface}

The spherical Japanese cedar pollen particle is shown in figure 4(a) (photo: $\times 3,000$ ), which was collected at trees growing in Akigase park. The airborne pollen particles are bigger than 20-30 $\mu \mathrm{m}$ at fresh condition and smaller than $15 \mu \mathrm{m}$ in diameter when dried after collection. From the view of surfaces of the perigonium, we can find heteromorphic grains with granular substances on perigonium and pollen surfaces, which are shown in figure $4(\mathrm{~b})($ photo: $\times 300)$. 


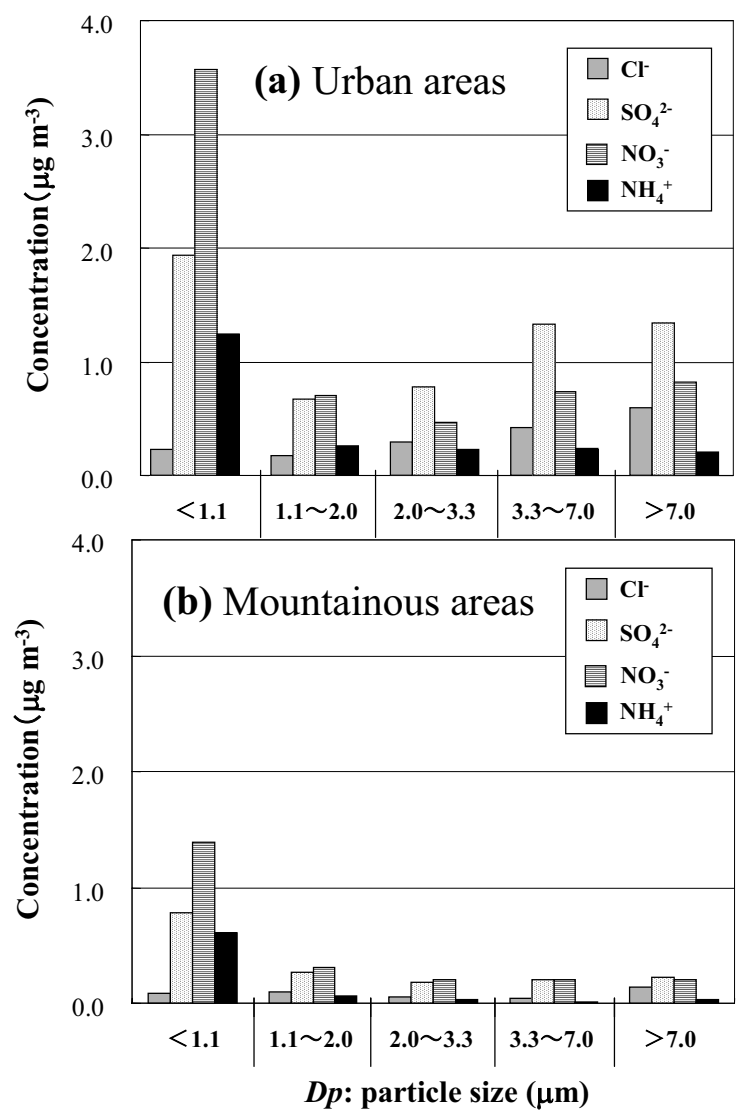

Figure 1: Size-distribution of the ionic concentrations of airborne particles collected in mountainous and urban areas.

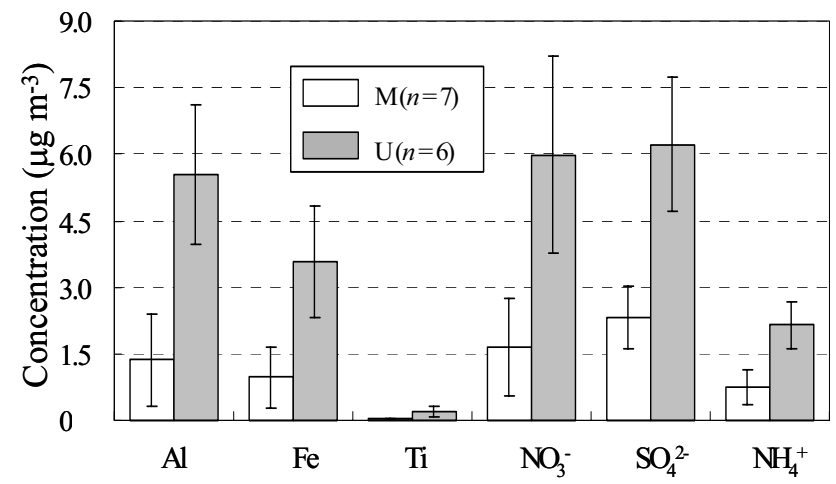

Figure 2: $\mathrm{Al}, \mathrm{Fe}, \mathrm{Ti}, \mathrm{NO}_{3}{ }^{-}, \mathrm{SO}_{4}{ }^{2-}, \mathrm{NH}_{4}{ }^{+}$average concentrations of airborne particles collected in mountainous (M: Okuchichibu) and urban (U: Saitama City) areas. The bars show the standard deviation. 


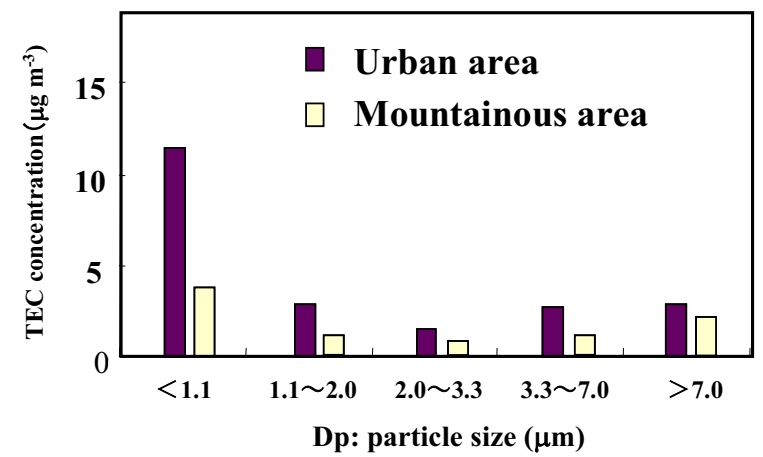

Figure 3: $\quad$ Size-distribution of TEC concentrations of air samples collected in mountainous (M) and urban (U) areas. TEC is total elemental carbon.
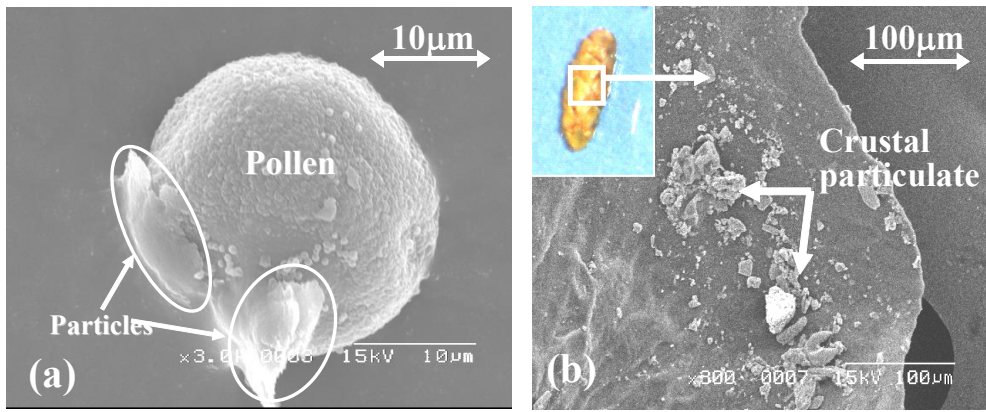

Figure 4: $\quad$ Scanning electron micrographs (SEM) of ambient pollen surfaces (a) which particulates are agglomerated onto the surface exposed to air pollutants in Urawa urban area, Saitama city, Japan and Cryptomeria japonica perigonium surfaces (b) collected in the urban area in our study.

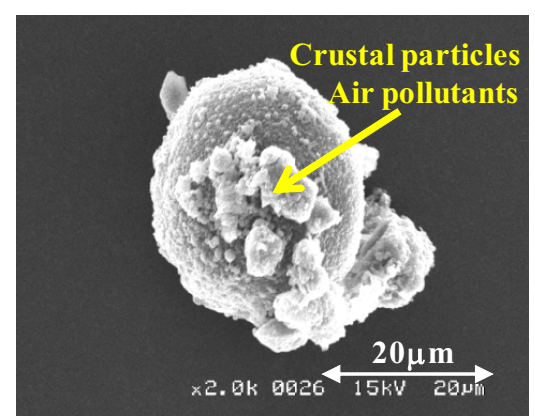

Figure 5: Scanning electron micrographs of pollen surface deposited with crustal and particulates. 
The granular substances are smaller than $1 \mu \mathrm{m}$ in diameter, they may be aggregated and a substantial amount of them belongs to the submicronic range as same as SPM. When pollen grains are transported and destroyed mechanically by any external force, qualitative change in shape of pollen (figure 5) observed by the SEM, which may induce allergen release.

\subsection{Pollen and allergen particles as bioaerosols and air pollutant deposition effect}

Sensitization to bioaerosols usually occurs across the mucosal surfaces of the gastrointestinal or respiratory tract or through the skin. In respiratory allergy, in which the airways constitute the prime site for allergic reactions, the ability of an allergen to become airborne is of particular importance. Bioaerosols are usually constituents of airborne allergen particles, either the original source (pollen particles, mite faeces etc.) or other types of particles (dust). The relative importance of the individual bioaerosol varies around the world, depending on climatic conditions and living habits. It is still not fully known in what way and to what extent airborne dust particles may contribute to asthma and respiratory symptoms, although some possibilities have been studied and discussed. It was suggested that SPM may generate both non-specific and bioaerosol-specific hyper-reactivity by provoking airway inflammation. A second possibility is that air pollutants such as SPM may modify the immune response by promoting IgE production. SPM has actually been shown to cause enhanced production of specific IgE to ovalbumin (OA) (Maejima et al. [13]). Moreover, DEPs, which is probably an important component of SPM, has also been found to have such an adjuvant effect (Maejima et al. [14]). This means that SPM, either in its entirety or only as individual particle types, may increase the production of specific IgE to environmental bioaerosols. The possibility has also been considered that airborne particles may carry bioaerosols in ambient air. This may be an important way of transporting bioaerosols into the lower respiratory tract. For these reasons, firstly, quantification and characterization of SPM should be carried out with regard to amount, as well as elemental and size distribution. Secondly, we should know how bioaerosols could be attached in vitro to gaseous and particle fraction of air pollutants.

\subsection{Influence of exposure gaseous and particulate pollutants}

We found high levels of crustal components such as $\mathrm{Al}, \mathrm{Fe}$ and $\mathrm{Ti}$ (Wang et al. [15]) of pollen in the urban area of Japan as given in table $\mathbf{1}$ and shown in figure 5 (photo: $\times 2,000$ ), the ratio of $\mathrm{Al}$ : $\mathrm{Fe}$ : $\mathrm{Ti}$ contained in pollen was 1: 1.06: 0.05 which is same as crustal source profiles determined in the previous study (Wang and Sakamoto [5]). In order to investigate the effects of air pollutants, we have conducted an exposure experiment of pollen to air pollutants in roadside. After a 9-hour exposure, pollen was analyzed by a light microscope and a scanning electron microscope. The morphological feature of the pollen is shown in (figure 4(a)). We found that agglomeration of particles attached to pollen surfaces although light and scanning electron microscopy did not reveal any changes in pollen structure or vitality for exposure times up to 9 hours. 
Table 1: $\quad \mathrm{Al}, \mathrm{Fe}$ and Ti concentrations of Cryptomeria japonica periponium pollen collected in mountainous (M) and urban (U) areas.

\begin{tabular}{ccccc}
\hline Site & & Al & Fe & Ti $\left(\mu \mathrm{g} \mathrm{m}^{-3}\right)$ \\
\hline M: Okuchcibu $(n=8)$ & n.d. $^{\text {a) }}$ & n.d. $^{\text {a }}$ & n.d. $^{\text {a }}$ \\
U: Saitama City $(n=8)$ & 1,070 & 1,140 & 52 \\
\hline
\end{tabular}

a) n.d. means below the limit of detection.

The particles attached to pollen surfaces are crystalloid and might be from secondary particles such as ammonium salts formed by acidic particles, gases and other alkaline substances. Agglomeration of SPM to pollen surfaces in areas with emission of organics (e.g., polycyclic aromatic hydrocarbons) deriving from fuel industry and automobiles is supported by semi-quantitative data confirming both a high degree of agglomeration as well as a high number of defect and destroyed pollen grains transported mechanically. From the data it can be concluded that gaseous pollutants $\left(\mathrm{NO}_{\mathrm{x}}, \mathrm{SO}_{2}\right.$ and $\left.\mathrm{NH}_{3}\right)$ shown in figure 6 adsorbed to the pollen, and crustal substances adsorbed to SPM can mediate agglomeration of particles onto pollen surfaces followed by modification of pollen and then, under appropriate conditions (e.g., humidity), may induce circumscribed local allergen release. One has therefore to take into considerations that in regions with high air pollution, particles are not only carriers of pollutants but also of bioaerosols. In the other words, pollen grains are not only carriers of bioaerosols but also of air pollutants.

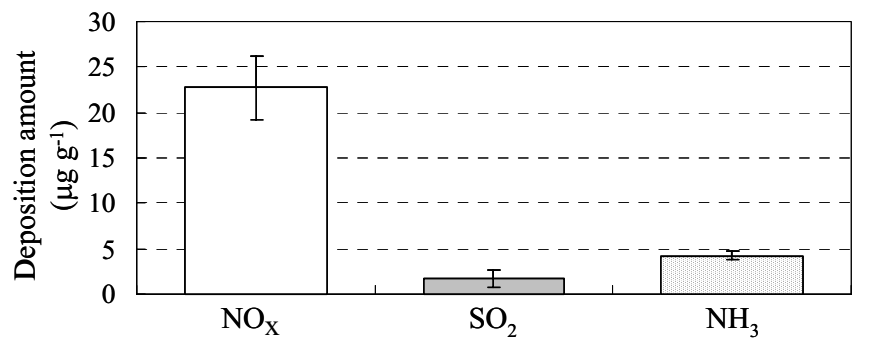

Figure 6: Amount of deposition of $\mathrm{NO}_{\mathrm{x}}, \mathrm{SO}_{2}, \mathrm{NH}_{3}$ exposed to Cryptomeria japonica pollen $(\mathrm{n}=3)$. The bars show the standard deviation.

The results obtained by the electron microscopy show that substances that may be present in the aqueous phase of SPM induce the release of allergen proteins from pollen grains and give rise to the formation of fine allergen particles $(D p<1 \mu \mathrm{m})$ (Wang et al. [16]). These particles are similar to those seen on the pollen surface in regions highly polluted by combustion products. DEPs which are likely the main elemental carbon component of SPM were also found to adsorb pollen bioaerosols in vitro. 


\subsection{Analysis of pollen ingredient and influence of respiratory system on air pollutants and cedar pollen allergen}

As mentioned above, after various processes, pollen ingredient may get through leakage, and may induce allergen release. In this study, concentrations of carbon $(\mathrm{C})$, hydrogen $(\mathrm{H})$ and nitrogen $(\mathrm{N})$ of the cedar pollen were determined with a $\mathrm{CHN}$ corder. We found that about $40 \%$ (relative standard deviation of the pollen exists as total carbon (C) or as carbonaceous contents which is apparent organic carbon (OC). At the same time, $6.27 \%$ of hydrogen $(\mathrm{H})$ and $0.84 \%$ nitrogen $(\mathrm{N})$ were also analyzed. Maejima et al. (2000) investigated ingredient and content of pollen when they were exploded, and found metallic contents of aluminum, calcium, iron, sulfur and TC were $0.049 \%, 0.3 \%, 0.035 \%, 0.033 \%$ and $37.2 \%$, respectively (Japan Automobile Research Institute [1]). The total carbon is well matched with other studies.

Since the pollen which had been collected from trees near the road with heavy traffic are agglomerated with the roadside polluted atmosphere, and as a results, pollen were exposed to a relatively high amount of ionic components of particles (figure $7, \mathrm{NO}_{3}{ }^{-}, \mathrm{SO}_{4}{ }^{2-}$ and $\mathrm{NH}_{4}{ }^{+}$), organic substances and SPM in heavy traffic regions, with adsorption of the pollen.

During the pollen flying seasons, it can be assumed that some of carbonaceous contents may come from pollen ingredient. Most of such granular substances are even smaller than $1 \mu \mathrm{m}$ in diameter $(D p<1 \mu \mathrm{m})$. The contribution of pollen ingredient to carbonaceous contents of SPM cannot be negligible. It was suggested that carbonaceous components of pollen may be one of the major OC contributors of suspended particles during the pollen flying seasons.

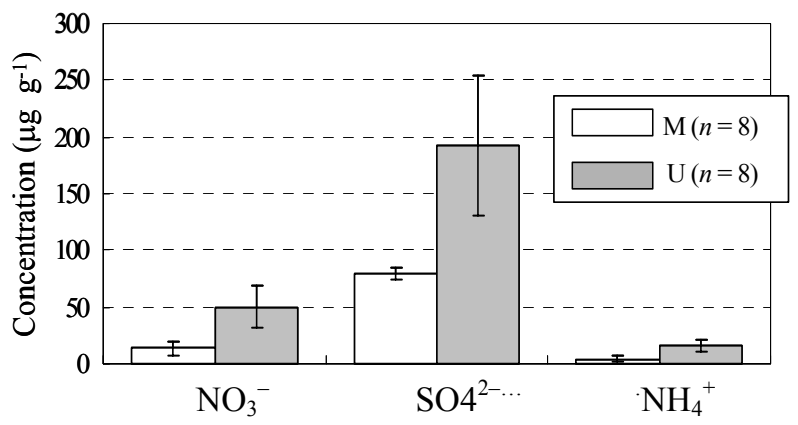

Figure 7: $\mathrm{NO}_{3}{ }^{-}, \mathrm{SO}_{4}{ }^{2-}, \mathrm{NH}_{4}^{+}$concentrations of collected Cryptomeria japonica periponium pollen in mountainous (M) and urban (U) areas. The bars show the standard deviation.

As mentioned above, the concentrations of TEC, TOC, $\mathrm{SO}_{4}{ }^{2-}, \mathrm{NO}_{3}{ }^{-}$and $\mathrm{NH}_{4}{ }^{+}$in fine particles below $2.0 \mu \mathrm{m}$ in air polluted urban area were higher compared with those in mountainous area. Higher concentrations air pollutants will be presumed to deposit on the Japan cedar pollen grain and its periponium. Furthermore, after cedar pollen disperses from a male and reaches the respiratory 
organs of a human body, it is suggested that allergen particles are possible to release from exfoliated Ubisch bodies which may be deposited and modified with air pollutants.

In this study, based on morphological observation for pollen grains, perigonium and its surface flying from mountainous area to urban area, it is possible to explain the morphological change processes in particle sizes by the form change accompanying resuspended circles, and the form change SEM observation result was illustrated to figure 8(a)-(f). Therefore, the bronchus branch of a human body and a possibility of reaching to an alveolus are also considered for the cedar pollen splinter group the water soluble ions carried out, the adjuvant activity which induces allergy reinforcement in multiplication causes, and it can guess becoming easy to show the symptoms of hay fever. However, the water-soluble ionic contents may be possibly formed from the gaseous pollutants during the deposition on the cedar pollen surface, it is necessary for the further examination.

About the coarse particulate matter $(D p>7 \mu \mathrm{m})$ concentration by which selfpossessed is carried out into the nasal cavity of a human body, comparison examination was carried out with urban site and a mountains background.

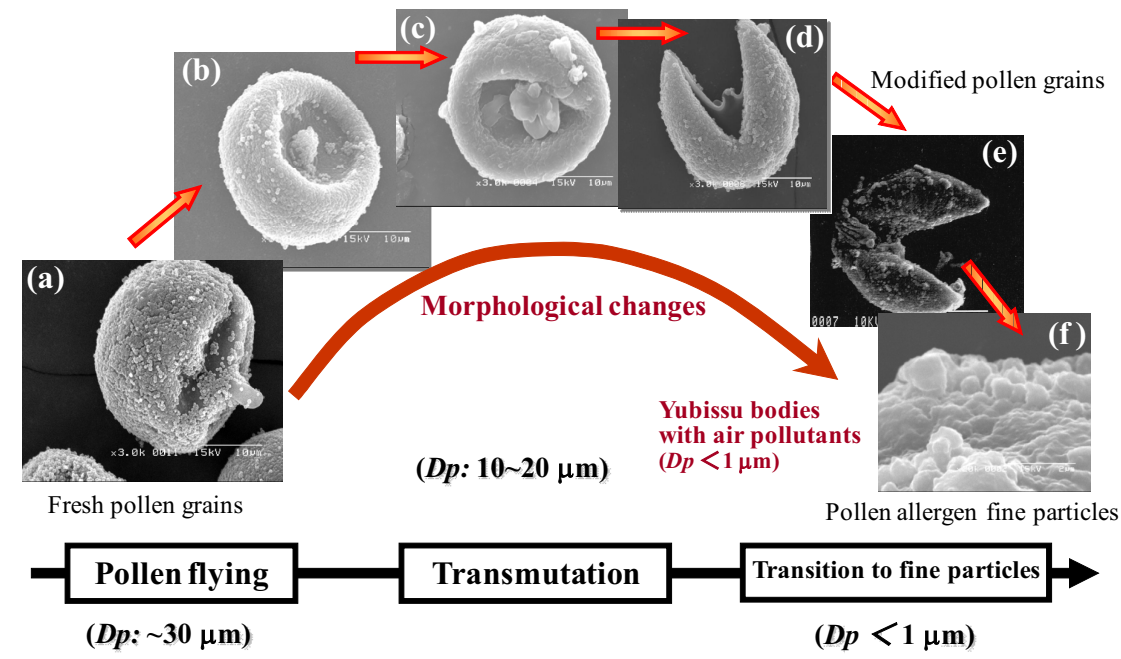

Deposition and modification processes during transportation

Figure 8: Morphological changes, deposition and modification processes of Cryptomeria japonica pollen during airborne transport to or within the urban area of Saitama, Japan. (Here, $D p$ : particle sizes.)

In the urban area, it was presumed that about 4 times as high air particulate matter as this carried out self-possessed into a nasal cavity, and the ingredients whose concentration was the highest were crustal components, such as $\mathrm{Al}$ and $\mathrm{Fe}$, at both areas. Moreover, with the Japan cedar pollen grain, perigonium collected in urban air polluted area, and especially pollen grain, as already shown 
in table 1, since $\mathrm{Al}$ and Fe were measured highly, cedar pollen and crustal particles carry out self-possessed into the same nasal cavity were clarified. In the mixed exposure experiment of the crustal particles such as the Kanto loam particles (mainly contained $\mathrm{Fe}_{2} \mathrm{O}_{3}, \mathrm{Al}_{2} \mathrm{O}_{3}$ and $\mathrm{SiO}_{2}$ ) and cedar pollen using a animal test in which influence clear to the specific multiplication reaction of the amount of Japan cedar unique IgE antibody generation which participates in the onset of hay fever directly, the rate of a positivity, and a neck lymph gland cell is accepted. In addition, long rage transportation phenomena of yellow sand and crustal dust from East Asian continent are recently reported by Lu et al. [17] during the pollen flying seasons in Japan due to the global warming. A possibility of having a bad influence on the onset of the hay fever to the cedar pollen of the crustal components containing Al, Fe, etc. depended calmly can be considered.

\section{Conclusion}

From the exposure experiments and observation, it is suggested that air pollutants adsorbed to the mediate agglomeration of particles onto Cryptomeria japonica pollen surface followed by modification of the air deposited pollen grains. Under appropriate conditions, i.e., humidity, gaseous and water-soluble compounds of SPM may induce local allergen release, resulting in-either allergenic extrusion below $1 \mu \mathrm{m}$ in diameter followed by generation of bioaerosols or in adsorption of pollen-derived proteins to airborne particulates. This view is supported by findings of Behrendt et al. [18]. Therefore, one has to take into consideration that in regions with high air pollution SPM is not only a carrier of pollutants, but probably also of altered bioaerosols, and that pollen are not only carriers for bioaerosols, but also for deposited air pollutants such as $\mathrm{NO}_{3}{ }^{-}, \mathrm{SO}_{4}{ }^{2-} \mathrm{NH}_{4}{ }^{+}, \mathrm{NO}_{2}, \mathrm{SO}_{2}$ and $\mathrm{NH}_{3}$ and so on. This is a synergistic effect of agglomeration of particles onto Cryptomeria japonica pollen surface. Therefore, pollen counts may not necessarily reflect the actual bioaerosols in outdoor and indoor atmosphere. Finally, it is emphasized that carbonaceous contents of Cryptomeria japonica pollen may be one of the contributors of suspended particles during the pollen flying and pathogenic seasons. These phenomena and evidences may affect pollinosis and are necessary to investigate their biomedical effects such as bioreactivity and hypersensitivity. Concentrations of bioaerosols and allergen released from Cryptomeria japonica pollen in different particle sizes will be determined in our further research.

\section{Acknowledgements}

Some works of this study are supported by the Special Funds for Basic Research (B) (No. 17310031, FY2005-FY2007) and Innovative Area Research (No. 20120015, FY 2008 FY2013) of Japanese Ministry of Education, Culture, Sports, Science and Technology (MEXT) and the FY2007-FY2008 Research project of Innovative Research Organization, Saitama University, Japan. 


\section{References}

[1] Japan Automobile Research Institute, Particles and Japanese cedar Pollinosis, Report of Japan Automobile Research Institute, March 2000, pp.1-159, 2000 (in Japanese).

[2] Bureau of social welfare and public health, Tokyo metropolitan government, The report of pollinosis sufferers, pp.22-25, 2007 (in Japanese).

[3] Uchiyama I., Kumae T., Arakawa H., Jinma M., Yokoyama E., Effects on Japanese cedar allergy by $\mathrm{NO}_{2}$ exposure, Pollen allergy and air pollution, pp.42-49, 1995 (in Japanese).

[4] Sakamoto K., Wang Q., Kimijima K., Okuyama M., Mizuno T., Yoshikado H. and Kaneyasu N., Behavior and source apportionment of ambient aerosols in early winter at South-Kanto Area, Japan, Chem. Express, 8, pp.345-348, 1993.

[5] Wang Q. and Sakamoto K., Spatial differences of carbonate components in soil and road dust and their relationship with ambient aerosol acidity, $J$. Aerosol Res., Jpn., 9, pp.345-353, 1994.

[6] Wang Q., Aoki D. and Sakamoto K., Basic observation on interaction between air pollutants and ingredient matter released from various pollens, The Paper of International Conference of Atmospheric Environment (Nanning, China), pp.234-242, 2003.

[7] Sakamoto K. and Wang Q., Behavior of chlorides and its sources of ambient aerosols in early winter at South-Kanto Area, Japan, J. Aerosol Res., Jpn., 13(2), pp.216-221, 1998 (in Japanese).

[8] Conner Teri L. and Norris Gary A., IgE adjuvant effect caused by particles-immediate and delayed effects, Toxicology, 156, pp.149-159, 2001.

[9] Behrendt H. and Becker W., Localization release and bioavailability of pollen allergens: the influence of environmental factors, Current Opinion in Immunology, 13, pp.709-715, 2001.

[10] Okuyama, Y., Matsumoto, K., Okochi, H. and Igawa, M., Adsorption of air pollutants on the grain surface of Japanese cedar pollen, Atmospheric Environment, 41, pp.253-260, 2007.

[11] Jiang Z., Wang Q., Sekiguchi K., Sakamoto K., Investigation of variations in SPM with enforcement of regulations on diesel vehicle exhaust in suburban Japan, JSME International Journal, 49, pp.2-7, 2006.

[12] Wang Q. and Sakamoto K., Receptor-oriented source apportioning and analyzing methods for ambient suspended particulate matter, CACS FORUM, 22, pp.10-19, 2002 (in Japanese).

[13] Maejima K. and Tamura K., Comparison of the effects of various fine particles on IgE antibody production in mice inhaling Japanese cedar pollen allergens, J. Toxicology \& Environmental Heath, 52, pp.231-248, 1997.

[14] Maejima K., Tamura K., Nakajima T., Taniguchi Y., Saito S. and Takenaka H., Effects of the inhalation of diesel exhaust, Kanto loam dust, 
or diesel exhaust without particles on immune responses in mice exposed to Japanese cedar pollen, Inhalation Toxicology, 13, pp.1047-1063, 2001.

[15] Wang Q., Aoki D. and Sakamoto K., Comparison of Air Pollutants in Japanese cedar perigonium pollen collected in Urban and Mountainous Areas, Paper of 45th Symposium of Japan Society for Atmospheric Environment (Akita, Japan), p.563, 2004 (in Japanese).

[16] Wang Q., Kurihara K., Kiryu H., Sakamoto K., Miwa M., Iwao Uchiyama I., Daily variation differences between airborne Japanese cedar pollen and its respirable allergen particulate matters during the most severe pollination seasons, EarozoruKenkyu, 23(2), pp.120-126, 2008 (in Japanese).

[17] Lu S., Wu M., Daily P., Yao Z., Sheng G., Fu J, The relationship between physicochemical characterization and potential toxicity of $\mathrm{PM}_{2.5}$ in Shanghai Atmosphere, Atmospheric Environment, 42, pp.7205-7214, 2008.

[18] Behrendt H. Becker W., Fritzche C., Sliwa-Tomczok W., Friegrichs K. and Ring J., Air pollution and allergy: experimental studies on modulation of allergen release from pollen by air pollution, Allergy and Immunology, 113, pp.69-74, 1997. 